\title{
A multi-scale integrated assessment model to support urban sustainability
}

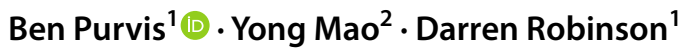

Received: 16 March 2021 / Accepted: 28 November 2021 / Published online: 14 December 2021

(c) The Author(s) 2021

\begin{abstract}
Tools purposed towards supporting the transition to more sustainable urban futures typically focus on specific phenomena at the local level. Whilst such approaches remain valuable, there is a need to complement this micro approach with broader integrated methods which deal with the interaction between different urban components as well as their relation to processes and policies enacted at higher scales. Through the adaptation of the World3 global model of Meadows et al. (The limits to growth, Universe Books, New York, 1972; Limits to growth: the 30-year update. Earthscan, London 2005), integrating both an urban system layer, and a national data layer inputting new data, we develop a proof-of-concept multi-scale integrated assessment model. This model is used to explore the relationship between the sustainability of the urban system relative to higher-scale contexts. By emphasising feedback, cascading effects, and unintended consequences, such a modelling framework allows for deeper consideration of coupling mechanisms between subsystems both within the urban system and across broader scales. Following the description of our model, we take Meadows et al. (2005)'s 'Scenario 3' as a starting point to generate several scenarios exploring potential intervention taken at the level of the individual urban system to tackle food security and localised pollution. Our results demonstrate that the evolution of the urban system is sensitively dependent on wider global events, and that while concerted intervention may mitigate some effects, the future of an individual system is largely at the mercy of the evolution of the global system. We argue that the results of this exercise suggest an important role for multi-scale models for informing the wider context of policy measures taken across different hierarchical scales. In an extended discussion section, we outline barriers and potential routes for building our work beyond a proof-of-concept relating to data, boundaries, politicisation, and building confidence in model outputs.
\end{abstract}

Keywords Limits to growth $\cdot$ Socioeconomic modelling $\cdot$ Simulation $\cdot$ System dynamics

\section{Introduction}

Urban sustainability is a ubiquitous concept, holding the focus of Sustainable Development Goal 11 within the United Nations' 2030 Agenda (UN 2015). With increasing levels of urbanisation, the 'urban challenge' remains one of the pressing issues of the twenty-first century (UN 2017). Urban areas

Handled by Vinod Tewari, Indian Institute of Management Bangalore, India.

Ben Purvis

b.purvis@sheffield.ac.uk

1 School of Architecture, University of Sheffield, Sheffield S10 2TN, UK

2 School of Physics and Astronomy, University of Nottingham, Nottingham NG7 2RD, UK dominate global resource use, they exhibit concentrations of great wealth, represent centres of innovation, community, activism, and change, but also exhibit areas of poverty, and concentrated pollution, placing pressure on surrounding land and a globalised commons for their continued functioning. Urban areas are thus a concentrated source of, and a key focus for potential solutions to the sustainability challenges facing the world (Angelo and Wachsmuth 2020).

Numerous methodologies exist for assessing urban sustainability (see Cohen (2017) for a review), but assessment of this state alone is insufficient; it is necessary to analyse system structure and processes to identify leverage points where intervention is best placed to bring about positive change (Bagheri and Hjorth 2007). This necessitates being mindful of the complexity of the urban context, and the possibility of unintended consequences from isolated policy decisions. The decentralisation of 'control' across 
the multiple levers of hierarchical governance, from local authority powers to national policy and international agreements, as well as more informal action, adds an additional layer of complexity. An integrated approach must consider this context and the interactions across these spatial and governance scales. By developing multi-scale integrated models which capture the socio-ecological functioning of the urban system, and its coupling to wider functioning across multiple scales, it is possible to both develop a greater understanding of urban sustainability and explore ways of improving upon it.

Ravetz (1998) suggests that methods at the sciencepolicy interface purposed towards decision making for the urban scale could benefit by learning from global integrated assessment models (IAM). Nordhaus (2013) defines IAM as "computerised dynamic models... that integrate knowledge from two or more domains into a single framework" (p 1070), typically across what Pauliuk et al. (2017) refer to as the 'global socio-ecological system'. Such models have become prominent tools within the climate science community to explore the socio-economic implications of mitigation strategies (van Beek et al. 2020). In this paper, we present a proof-of-concept model of this type exploring the adaptation of a global IAM to the urban scale.

To simplify this process, we selected an already existing global IAM as a basis for adaptation. For this purpose, we used the 'World3' model from the Limits to Growth (LtG) studies (Meadows et al. 1972, 2005), due in part to it being well documented and freely available online. Despite the original model predating the language of IAM, it is commonly seen as an early progenitor of the field and led to a proliferation of 'global models' in the decades after its first publication (Meadows et al. 1982; van Beek et al. 2020). It is considered relatively simple compared to more recent IAMs, and as such it has received attention in recent years from scholars who have been able to adapt it with relative ease (Pasqualino et al. 2015; Ansell and Cayzer 2018; Heath et al. 2019; Pasqualino and Jones 2020). Further, its structure is sufficiently general that it lends itself to the representation of smaller scale socioeconomic systems, if representations of flows across boundaries are introduced.

By downscaling and adapting World 3 to an urban scale model coupled to an aggregate global model, and an intermediate national layer, we have produced a proof-of-concept multi-scale model (illustrated in Fig. 4). Such a hierarchical model is well suited to testing policy interventions across different governance scales. By outlining the adaptation process undertaken in the development of this proof-of-concept model, we illustrate the assumptions made and barriers confronted through this development. After presenting several scenarios, examining the relation between the sustainability of the urban system relative to the wider systems in which it is situated, we discuss the virtues of this approach, open access to it, and the challenges inherent to producing a fully operational model with steps to confronting and overcoming them.

\section{Background}

\section{The limits to growth}

The publication of The Limits to Growth (Meadows et al. 1972) was integral to the growth of the sustainability movement, drawing attention to planetary boundaries in a new way (Lumley and Armstrong 2004; Gómez-Baggethun and Naredo 2015). Central to this report was a computerised model, 'World3', which sought to represent the global system as a complex web of interactions and feedbacks between five subsystems. By simulating the interaction of population, economic, agricultural, resource, and pollution subsystems, from 1900 to the end of the twenty-first century, the model produced a series of future scenarios with variations of business as usual, technological advancement, and social policy responses to an unravelling future. These scenarios were presented within $\mathrm{LtG}$ as graphical outputs showing the time evolution of key parameters, such as industrial output, food per capita, and population across the time window.

LtG used these scenarios to demonstrate and argue the unsustainability of a societal system founded upon exponential economic growth on a finite planet. The publication of the report spurred fierce debate following its conclusion that without significant efforts to enact change, 'business as usual' would lead to "sudden and uncontrollable decline in both population and industrial capacity" (Meadows et al. 1972, p 23). Despite criticism from numerous quarters (see, e.g., Cole et al. (1973) and Nordhaus et al. (1992)), the publication has arguably withstood the test of time, and the last decade has witnessed a growth in interest in the model and its outputs (Bardi 2011; Turner 2012; Pasqualino et al. 2015; Heath et al. 2019).

World 3 marked the first of a number of 'global models' that would be developed across subsequent decades (Meadows et al. 1982). Subsequent decades would thus see the rise of energy-economic modelling, and aggregated cost-benefit climate-economic models (van Beek et al. 2020). Whilst some of the scholars working within this domain maintained an adversarial relationship with LtG and World3 (Nordhaus 1973), the emergence of IAMs which are now commonly employed in the climate change literature, owed much to the pioneering work of Meadows et al.'s global scale environment-economic model (Capellán-Pérez et al. 2020). Nevertheless, the simulation methods employed by World3 have been largely marginalised within the IAM community in favour of optimisation and economic equilibrium modelling (Purvis 2021). 


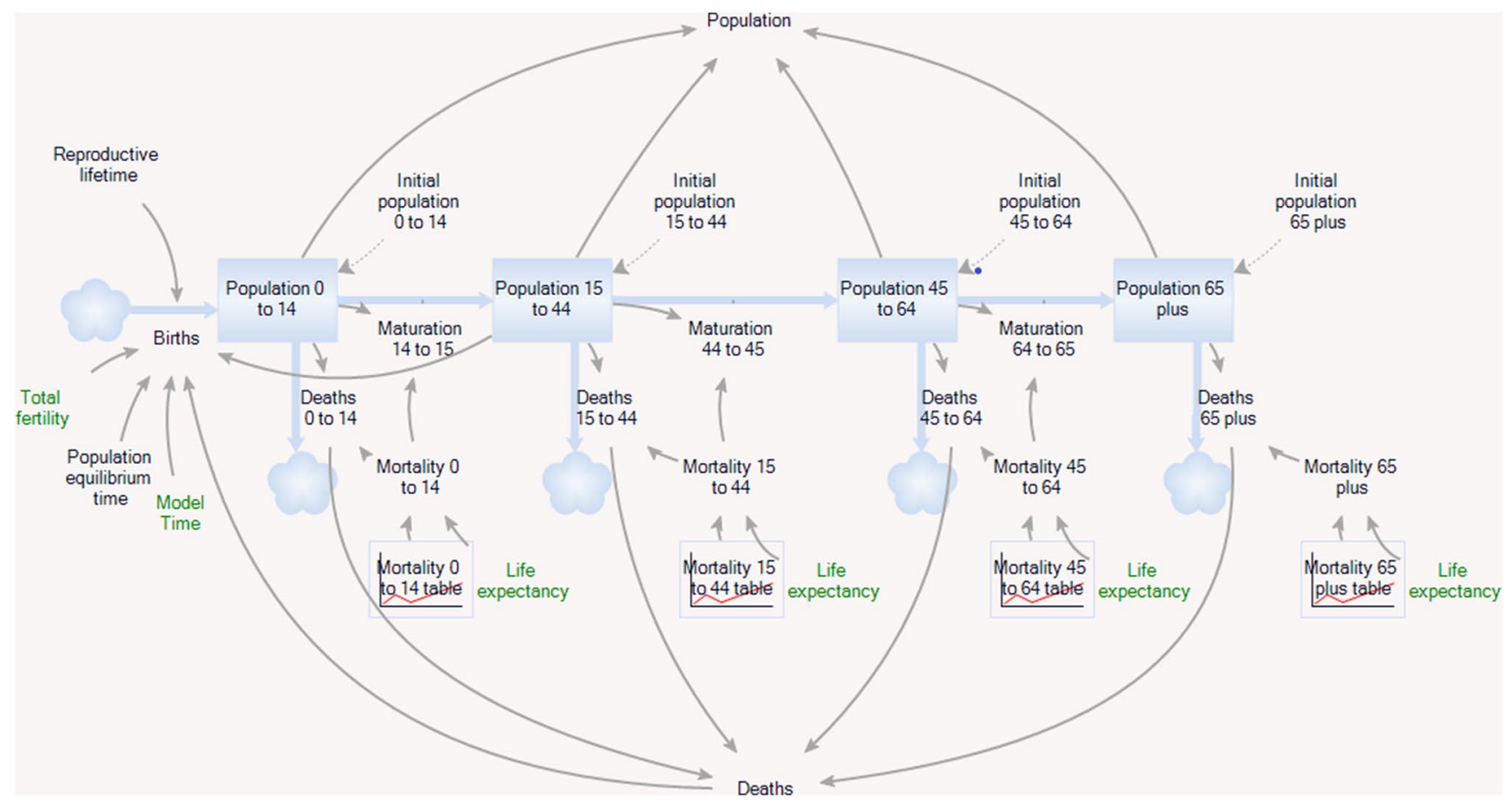

Fig. 1 Example stock and flow diagram within Ventity. The boxes and arrows between them show stocks and flows. The remaining parameters represent variables and table functions

\section{System dynamics}

The World3 model, central to LtG's argument, employed the modelling paradigm of 'system dynamics', developed by Jay Forrester, who had been integral to the project's commissioning (Forrester 2007). Used as both a heuristic, and a simulation methodology, system dynamics is built upon a web of coupled differential equations intended to describe the behaviour of the system of interest. By numerically solving these equations through a series of discrete time-steps, system dynamics software is able to describe the evolution of the system in question over a defined time period. Thus, the approach is particularly well-suited to modelling and understanding the behaviour of complex non-linear systems over time, from simple mechanical systems to large-scale socioeconomic systems (Lane and Videira 2019).

System dynamics simulation has evolved alongside the widespread use of graphical diagrams, notably stock and flow, and causal loop (see Figs. 1, 5 and 6 respectively), to describe and communicate system structure as a set of causal assumptions (Lane 2008). Indeed, system dynamics simulation software typically enables modellers to construct their models graphically, as shown in Fig. 1, with the underlying differential equations automatically constructed and solved by the software, based upon this graphical structure. This graphical focus allows for accessibility and ease of understanding, enabling users to develop and implement models in an intuitive manner which does not require explicit formulation of differential equations or advanced coding experience to structure and solve them.

Typically, system dynamics models contain four basic elements: stocks, flows, variables, and table functions (Sterman 2000). A stock represents an accumulated quantity, and flows influence its rate of change over time. Variables are described through functions which detail their dynamic dependence in relation to other model parameters and may incorporate time delays which introduce a lag between the output and input. Table functions are used to provide nonlinear functions relating two variables, mapping inputs as described by the interpolation of corresponding values in the table (Eker et al. 2014).

Uses of system dynamics are diverse, and as such there is no singular underpinning epistemology. Pruyt (2006) explores the basic philosophical assumptions of system dynamics both in theory and practice throughout the literature. From this he concludes that there are "several system dynamics practices that are characterised by very divergent basic assumptions", arguing that whilst the most mainstream strand can be interpreted as critical pluralist, other practices may be viewed as constructivist, postpositivist, pragmatist and transformative-emancipatory-critical (p 24). This diversity reveals the potential for system dynamics to offer an alternative to dominant techno-scientific modelling approaches that have been criticised in strands of critical urban literature for marginalising social and less quantifiable aspects of urban sustainability (Brenner and Schmid 2015; 
Fig. 2 Representation of the key inter-sector feedbacks in World3-2003

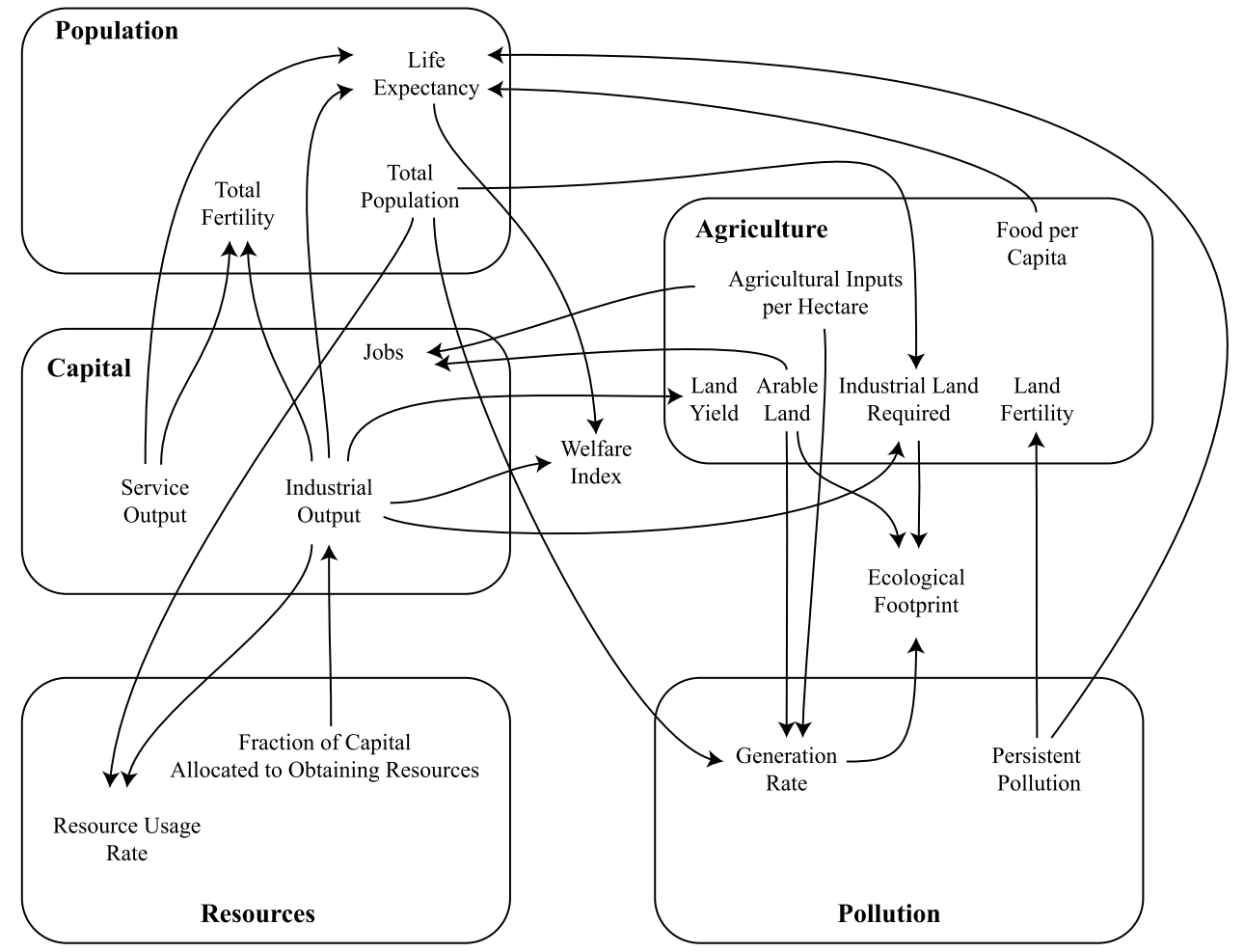

Opp 2017; Cauvain 2018). Further, through its emphasis on holistic thinking of the system as more than the sum of its parts it is well suited to integrated modelling (Verburg et al. 2016; Nabavi et al. 2017).

\section{World3}

The scope of World 3 is described within Meadows et al (1974) (pp 9-13), with the selection of dynamic phenomena dictated by the 200 -year time horizon, and a level of complexity sufficient to "represent the mode of approach of the human population to the environmental carrying capacity" (p 10). The major interactions between the five sectors of the World 3 model are displayed in Fig. 2. World3 contains seven groups of stocks describing global aggregate population, industrial capital, service capital, non-renewable resources, persistent pollution, land, and land fertility. World3 was initially built using the now defunct Dynamo software, but copies are available freely online that are built within the Vensim software package (Fiddaman 2010), as is a copy which we have built using Ventity 3.0. ${ }^{1}$ A detailed manual providing full details of the model's causal structure, data, assumptions, and equations is also provided by Meadows et al. (1974).

\footnotetext{
1 This is available within our figshare repository detailed within this article's Electronic Supplementary Material.
}

The model's population stock is mediated by total fertility, which itself is a function of the level of service and industrial output, as well as mortality multipliers from food availability and persistent pollution (Meadows et al. 1974, pp 45-55). Within the capital sector, physical industrial capital (e.g., machines and factories) is used to manufacture and produce industrial output (the stream of consumer goods and investment goods). This annual industrial output is allocated across the sectors of the system in the form of consumer goods, resource obtaining capital, agricultural capital, service capital, and reinvestment in industrial capital (Meadows et al. 2005). This capital degrades over time and must be routinely replaced.

The agricultural sector consists of land which may be developed using agricultural capital to produce arable land to grow food. This arable land erodes irreversibly over time at a rate determined by the intensity of its use if no preventative measures are taken and may also be developed into urban land to satisfy the demands of industrial production (Meadows et al. 1974, pp 263-268). The stock of nonrenewable resources decreases over time as a function of industrial output; as the stock decreases the capital cost of accessing these depleted deposits increases (pp 377-387). Persistent pollution is produced by industrial and agricultural activities, the level of this pollution negatively affects life expectancy and land fertility (pp 422-427).

The $L t G$ (Meadows et al. 1972) and its subsequent updates (Meadows et al. 1992, 2005) present a series of scenarios representing potential future outcomes based upon differing 
assumptions. Each scenario builds upon the last, analysing the reasons for the previous collapse and implementing technological and policy measures within the model aimed towards mitigating the first limiting factor. This process acts to build a deeper awareness of the underlying dynamics and feedbacks, as well as the types of intervention that can be effective in moving towards a more sustainable future.

Recent adaptations of World 3 within the literature include Pasqualino and Jones (2020) who bridge the past 5 decades of theory, as well as including more detailed energy modelling to create their ERRE model. Similarly, Ansell and Cayzer (2018) adapt World 3 to explore climate change and energy production. Whilst the authors could not find any literature that directly applies the World3 model to the urban scale, there remain multiple recent studies which employ system dynamics to explore issues relating to urban sustainability (Kidwai and Saraph 2016; Macmillan and Woodcock 2017; Bach et al. 2019; Tan et al. 2018).

\section{Modelling framework}

The purpose of the model detailed in this work is to represent the sustainability, broadly understood, of an urban system in relation to the global system's sustainability, and policy action across broader scales. In its current form as a proof-of-concept, it is intended to allow for exploratory modelling of the multiple scales influencing the urban, and to be used as a learning tool for better understanding the nature of the sustainability challenge at the urban level. It is further intended to demonstrate the potential of multi-scale integrated assessment modelling to inform policy. These intentions define the initial model's scope, and suggest the level of abstraction that is appropriate, with the primary focus being given to the urban scale. This scope is limited by our use of World3 as a basis for the urban system, meaning much of the 'urban-ness' of this level is not explicitly represented in this model iteration. To test that our proofof-concept model is fit for purpose then, it should be able to demonstrate reasonable output evolution of encoded variables under a range of scenarios relating to assumptions about the future at broader scales.

It is hypothesised that a full model, built collaboratively with relevant stakeholders, would be well-suited to aiding decision-making in the formation of local policy, as well as developing an appreciation for the need of joinedup thinking in this area. Such a model would be able to explore possible medium to long term consequences at the local scale of proposed policy measures, in particular highlighting unintended consequences that might occur due to feedback effects and interaction of the urban system with broader scales. Such a multi-scale model could also be purposed towards exploring more theoretical questions which involve translation across scale, such as the impact of a 'green new deal' on the urban economy, or how a 'steady state society' may be structured at different governance levels. In this manner, such a 'bottom-up' approach would complement the current global scale focus of the IAM field.

\section{High-level model structure}

The present incarnation of our model rests on the assumption that the urban system may be represented abstractly as a successively downscaled global system with opened boundaries, and sub-systems which interact across scale. As such the urban layer of our model bases itself on a downscaling of Meadows et al.'s (2005) World3-2003, thus the 'urban-ness' is largely implicit. As a proof-of-concept for demonstrating the potential of a multi-scale approach, this limited level of abstraction based upon hierarchical downscaling is, we suggest, sufficient for this purpose. Indeed, Meadows et al. (1972) argue that the structure of their model is sufficiently general to represent a city subject to the addition of migration and trade flows across its boundaries (p 104). Our model contains three hierarchical scales relating to the urban, national, and global scales.

Figure 3 details the high-level structure of the coupled model, showing the three modular hierarchical level entities, their associated sectoral subsystems, and the crosshierarchical dependencies. As indicated by the arrows in between hierarchical levels, the coupling between these levels is monodirectional for now, meaning the behaviour of the lower scales does not inform the behaviour at higher scales. Whilst this was primarily done for reasons of computational brevity, it was informed by the logic that the impact of a single small urban system (population of order $10^{5}$ ) has negligible impact on the evolution of the global system (population order $10^{9}$ ). Also shown, to the left of the figure are the initialisation inputs which dictate the initial size of the urban level.

The global level does not deviate significantly from World3-2003. As can be seen within Fig. 3, the urban level contains 5 sectors representing demographic, capital, resource, pollution, and food systems. It therefore behaves in much the same way as the global level, following our description of World3 above. The national level, sandwiched between global and urban levels in Fig. 3, is for now limited to inputting initialisation and time series data and experiences no endogenous feedback, acting as an intermediary between the global and urban levels. A more complete description of parameters and variables can be found within the Electronic Supplementary Material. 
Fig. 3 High-level model structure displaying the dependencies of the hierarchical entities. Note that the arrowheads denote the direction of coupling between levels: only the resources system includes bidirectional coupling as discussed in text

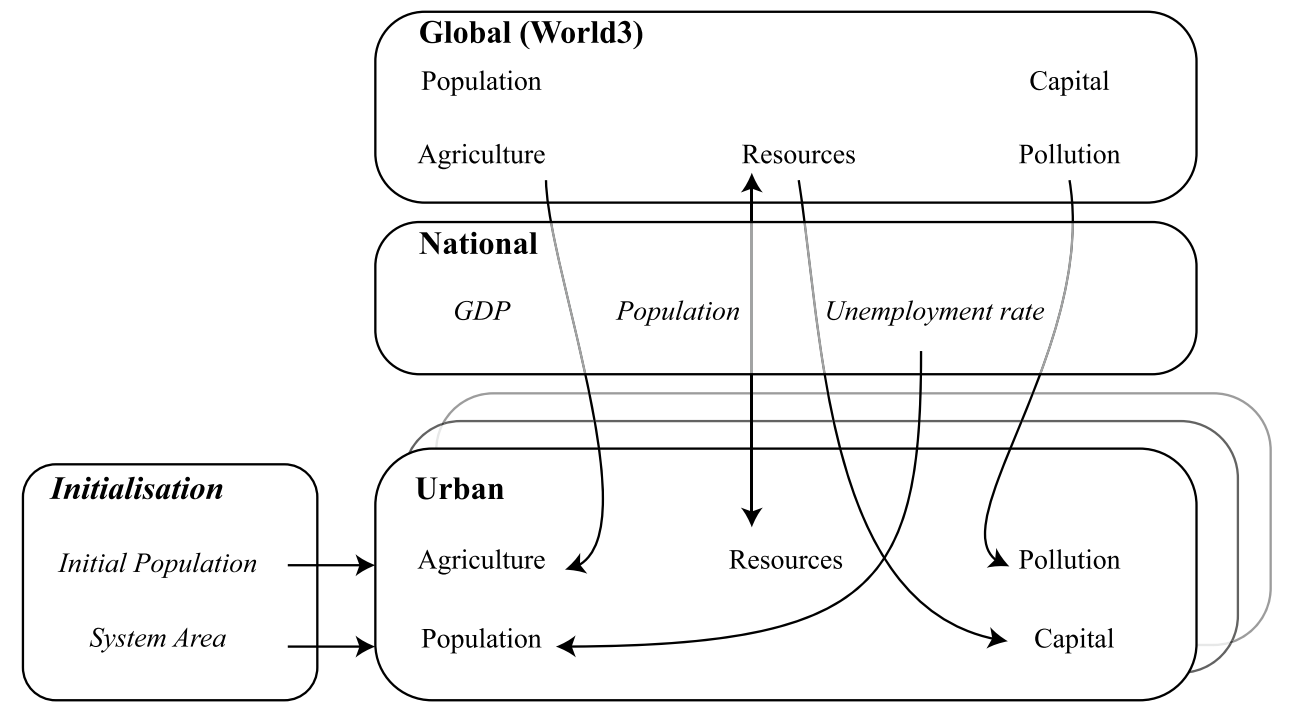

\section{Data}

The current model creates a synthetic urban representation scaled from national UK data, with the UK representing a natural choice due to our familiarity of the context and the demands of funding stipulations. The primary data set used for this purpose was version 3.1 of the Bank of England's 'A millennium of macroeconomic data' (Thomas and Dimsdale 2017). For a proof-of-concept, this synthetic data set provides a generalised picture freed from details of a particular local context, bypassing the need to infer time series data through statistical techniques, and allowing us to focus instead on the methodology more broadly. This is sufficient at this exploratory stage since we are not yet interested in generating any contextually specific results. The use of contextual urban data is discussed in "Data and noise". Further details of the data used in this exercise are available within this paper's Electronic Supplementary Material.

\section{Software}

The model presented here uses the Ventity 3.0.2 software package (Ventana Systems 2020). Ventity utilises 'entities', whose entity 'type' corresponds to class definitions within object-oriented programming (Yeager et al. 2014). This functionality is particularly useful for our purposes, as it allows for modularity and scaling with relative ease. Within this framework we created 3 entity types; 'World', which contains a singular entity, a copy of Meadows et al.'s World3-2003; 'National', which for the time being hosts various exogenous data in a singular 'UK' entity; and 'Urban', which describes the downscaled World3 model. It is thus possible to run multiple Urban entities in parallel with varying parameters to represent a set of urban systems, and similarly to create other National entities which contain different national data sets. Such a structure lends itself well to collaborative development, with other researchers being able to contribute additional national and urban models, allowing the system to grow organically, through the managed figshare repository. This is something which is not easily replicable in other system dynamics software packages.

\section{Methodology: adapting World3}

This section describes how our model was developed. An overview of our methodology to develop this proofof-concept model as an adapted version of World3 is sketched in Fig. 4. This process consisted of first rebuilding World3-03 within the Ventity software; initially the 'World' entity type was created by rebuilding World3-03,
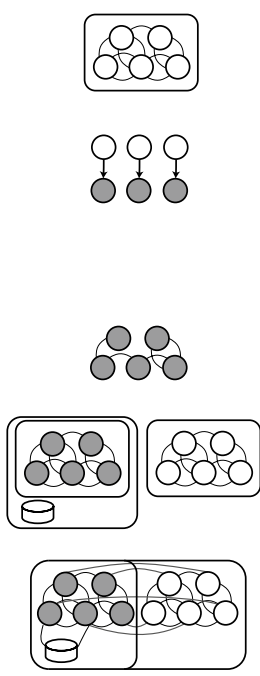

1) Rebuild World3-03 $>$ Verify

2) Adapt each subsystem in isolation $>$ Identify variables for calibration $>$ Identify data sources $>$ Calibrate $>$ Validate

3) Couple subsystems $>$ Validate

4) Introduce Global and National level systems (World3-03 and data layer)
5) Couple subsystems $>$ Verify $>$ Validate
6)Validate whole model
7) Produce scenario outputs

Fig. 4 Outline of our methodology 
Table 1 Summary of how the urban level of our model differs from the World3 model which was used as its basis

\begin{tabular}{ll}
\hline Subsystem & Description \\
\hline Population & $\begin{array}{c}\text { Causal structures for population growth and decline via migration are added (Fig. 5). Recalibration of healthcare and } \\
\text { life expectancy parameters }\end{array}$ \\
Jobs sector recalibrated using UK data. Parameters added relating to employment for links with migration causality \\
Agriculture & $\begin{array}{l}\text { Fix for depletion of arable land; allowed conversion of arable land to urban industrial land. Causal structure added to } \\
\text { allow the urban system to import food from the wider global system }\end{array}$ \\
Resources & $\begin{array}{l}\text { Urban resource usage linked to global stock, there is no dedicated urban resource stock } \\
\text { Persistent pollution } \\
\text { Indicators }\end{array}$ \\
Controls & $\begin{array}{l}\text { Addition of urban footprint cf. ecological footprint; addition of indicators comparing resource usage to global average } \\
\text { Input of } 1900 \text { population and area used to determine initialisation parameters across subsystems }\end{array}$ \\
\hline
\end{tabular}

and cross-comparing this with a copy of Meadows et al (2005)'s World3-2003 model for verification. This was then replicated and renamed to 'Urban' to provide a base structure for downscaling and adapting from step 2. Adapting each World3 subsystem in isolation involved considering variables which required recalibration with UK and contextual urban data and validating each subsystem alone before recoupling them. A base calibration thus downscaled this entity type by changing the initial values of each stock to values consistent with an urban sized system with a population in 1900 of 300,000 people, roughly corresponding to medium sized industrial cities at the time, such as Nottingham or Bristol (Clayton and Mandair 2012). This resulted in an urban level copy of World3-03, largely following the process outlined in Meadows et al. (1974) in calibrating and validating.

With a standalone urban system created, the fourth step involved introducing global and national level systems and thereby reconsidering how the causal structure of each subsystem would be impacted in the coupling of these levels together. Thus, step 5, coupling subsystems, included both recalibration of variables, and the introduction of new structures where appropriate. Of crucial consideration to the causal mechanisms adapted here was the implications of moving from a closed global system model to an open urban system model. During this step, causal structures for migration and food import were added.

Our approach to calibration and validation is iterative, as indicated in Fig. 4. The parameters calibrated within the original World3 model were each revisited at various stages to judge whether their calibration as outlined in Meadows et al. (1974) remained appropriate. We take a critical and pragmatic approach to validation, recognising that "is the model useful?" remains the most important question in this respect. Due to the nature of simulating future trends, we rely strongly on 'face validation' (Ford 2010), i.e., does the output make sense and cohere to a potential reality. We recognise that face validation is a limitation of this modelling paradigm and so, following
Meadows et al. (1974, 2005), we also simulate 200 years from 1900 to have historical data to which we can compare our scenario runs.

\section{New causal structures}

Table 1 outlines the major changes between the initial World3-03 model and the newly created urban level, by subsystem. This includes the addition of causal structures relating to migration and food, as detailed below. Table S2 within the Electronic Supplementary Material details additional parameters which have been added to the urban level.

\section{Migration at the urban level}

A basic population model based on natural growth and mortality is no longer appropriate at the urban scale, as we must consider the inflow and outflow of people into the urban system. This necessitates developing a basic urban migration model. There are numerous pre-existing variables within World3-03 that may be selected to parametrise the net migration flow (Etzo 2008). A 2016 report on UK internal migration reveals that this population movement is dominated by the age groups defined in World 3 as working age (i.e., 15-44) (Office for National Statistics 2016). We therefore base our migration model in terms of a 'relative unemployment rate' variable, which describes the difference between the model's calculated unemployment rate, and the national unemployment rate given by data built into the UK entity. This is further moderated by an urban population density multiplier which is intended to act as a proxy for housing availability. A causal loop diagram illustrating the assumptions of our migration model is presented in Fig. 5; growth in capital leads to more jobs, lowering the urban unemployment rate, creating a net flow of migration into the urban area if this becomes lower than the national rate. 


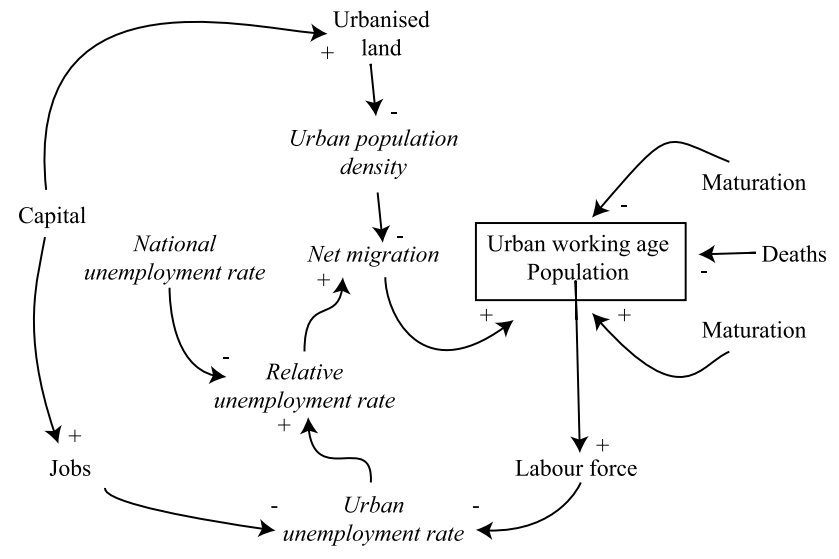

Fig. 5 Causal loop diagram for migration model, added structures are represented in italic font

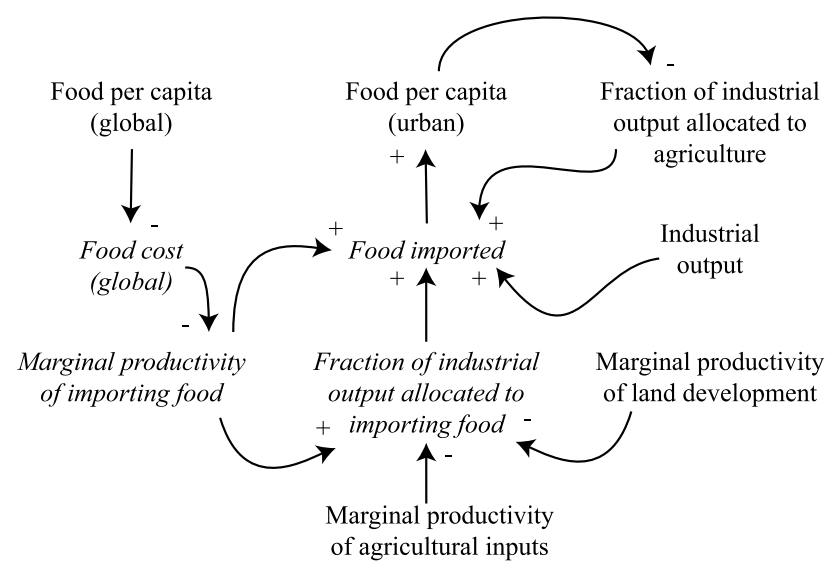

Fig. 6 Causal loop diagram for food import

\section{Food systems at the urban level}

Urban systems across the world are increasingly reliant on national and international sources for their food supply (Puma et al. 2015). It is therefore necessary to introduce a market mechanism for the import of food into the urban system. The mechanisms we developed for this are displayed in the form of a causal loop diagram within Fig. 6. This additional causal structure involves updating the existing allocation mechanisms built into the original World3-03 basis for the urban level structure so that the system shifts its food source towards importing food into the urban system if such a process is economically more advantageous. Here, input from the global scale model is used to determine a world food cost relative to the cost of food grown locally. Whilst the national level may be used to mediate the effective 'global cost' of food through tariffs and subsidies, since we initially consider only a single urban system this has not been fully implemented.

\section{Scenarios}

The scenario outputs presented here display key parameters in individual plots, with the urban system value plotted alongside the global average value from the World entity output where scales allow. A time horizon from 1900 to 2100 was employed equivalent to that used by Meadows et al (1972, 2005). This allows for more direct comparison with Meadows et al.'s scenarios, as well as for empirical validation for the initial simulation period against historical data, and the 2100 date remains relevant due to global climate change goals. For these scenarios we used a single urban system within our analysis, with its size following our base calibration to a population in 1900 of 300,000 people, and a land area of 100,000 ha. ${ }^{2}$

\section{A standard run}

Following the calibration process described above, a reference scenario run was produced. This is described as the model's 'standard run' and represents the "likely general behaviour mode of the system" if policies remain similar in the future, and the uncertain numbers of the model are roughly correct (Meadows et al. 2005, p 71). It uses Meadows et al.'s (2005) Scenario 3, which has been described by Randers (2012), as the closest scenario to what has been borne out in reality ( $\mathrm{p}$ 304). This global scenario is described in Meadows et al. (2005) pp 210-214; an ample supply of non-renewable resources, and increasingly effective pollution control technology allows for a sustained growth in welfare into the latter half of the twenty-first century. Nevertheless, food production begins to decline from around 2070 due to the impact of pollution on soil fertility, as well as a decrease in arable land due to erosion and urban sprawl. Within the scenario, this food crisis draws capital from the industrial sector until a tipping point is reached at which investment is insufficient to offset depreciation, leading to a sudden collapse in welfare.

We use a spreadsheet to initialise the input data for each scenario. This sets the values of key parameters that the scenario is produced from, as outlined in Table 2. After the model is initialised with this input data, the simulation is run over the 200-year time window, with the resulting data output collected in a second spreadsheet which records the value of every parameter within the model at each time step. Figures 7, 8 and 9 display graphical outputs of relevant parameters from this data plotted using $\mathrm{R}$. We follow

\footnotetext{
2 It was necessary to include a 'hinterland' (Fujita and Krugman 1995) within our conceptualisation of the urban system's bounds here, since at this abstract proof-of-concept stage there is no intermediate system for food production between the urban and global levels.
} 
Table 2 List of scenarios which we present in this paper alongside details of the parameters used to produce them

\begin{tabular}{|c|c|c|}
\hline Scenario & Description & $\begin{array}{l}\text { Parameters within urban entity (reference scenario } \\
\text { values bracketed) }\end{array}$ \\
\hline Reference scenario (Fig. 7) & $\begin{array}{l}\text { Our baseline scenario. The urban system grows with } \\
\text { a high level of welfare before global food and eco- } \\
\text { nomic crises lead to a sharp decline in the } 2070 \mathrm{~s}\end{array}$ & \\
\hline Food resilience Scenario (a) (Fig. 8) & $\begin{array}{l}\text { Urban food resilience policy accompanied by invest- } \\
\text { ment in high-cost yield enhancement. The system } \\
\text { continues on a similar trajectory to the reference } \\
\text { scenario but the decline in food per capita at the } \\
\text { urban level is dampened }\end{array}$ & $\begin{array}{l}\text { Yield tech time }=2020(2100) \\
\text { Yield tech cost }=10(1) \\
\text { Yield tech effectiveness }=10\end{array}$ \\
\hline Food resilience Scenario (b) (Fig. 8) & $\begin{array}{l}\text { Urban food resilience policy accompanied by invest- } \\
\text { ment in low-cost yield enhancement. The system } \\
\text { continues on a similar trajectory to the reference } \\
\text { scenario but the decline in food per capita at the } \\
\text { urban level is dampened }\end{array}$ & $\begin{array}{l}\text { Yield tech time }=2020(2100) \\
\text { Yield tech cost }=1(1) \\
\text { Yield tech effectiveness }=10(1)\end{array}$ \\
\hline Food resilience Scenario (c) (Fig. 8) & $\begin{array}{l}\text { Urban food resilience policy implemented through } \\
\text { shifting demand without technological investment } \\
\text { to enhance yield. This has disastrous effects lead- } \\
\text { ing to a sharp decline in food per capita }\end{array}$ & $\begin{array}{l}\text { Policy Year } 2020(2100) \\
\text { Fraction of industrial output allocated to agricul- } \\
\text { ture }=0.5 \text { (usually variable, this scenario forces it } \\
\text { to a constant) }\end{array}$ \\
\hline Pollution controls (Fig. 9) & $\begin{array}{l}\text { Investment in pollution reduction technologies at } \\
\text { the urban level }\end{array}$ & $\begin{array}{l}\text { Policy Year }=2020(2100) \\
\text { persistent pollution technology change time }=2020 \\
(2100)\end{array}$ \\
\hline
\end{tabular}

the approach of Meadows et al. (2005) in interpreting these outputs qualitatively, by providing a narrative description of what is observed. In some cases, we have explored the evolution of parameters through causal tracing, to be able to present a detailed understanding of what is taking place within each scenario.

Outputs of key parameters in our reference scenario are displayed in Fig. 7, where the blue lines represent global parameters, and those in orange are equivalent parameters within the urban system. This reference scenario sees steady growth of the urban population (d) and economy (b) through to 2070 when the system experiences the impacts of a global decline. The level of welfare (a) within our urban context remains high throughout most of the scenario, above the global average, as is consistent with the UK context (UNDP 2020). It suffers a slight dip in the mid-twenty-first century, as increased global food negatively impact on life expectancy. This impact is dampened relative to the global picture due to the relative wealth available for purchasing and importing food.

The population growth of the urban system (d) is driven by inward migration as workers relocate to take up available jobs within the urban economy. The total fertility settles at around 1.3 from the $1990 \mathrm{~s}^{3}{ }^{3}$ A short-lived decline due to outward migration is witnessed within the scenario during

\footnotetext{
3 The UK average fertility after steady decline settles around 1.7 (Office for National Statistics 2019), although there is evidence that this value is lower in urban areas (Kulu 2013).
}

the 1960 s as the industrial output per capita equilibrates, representing a loss of jobs in the urban industrial sector, but this does not lead to extended decline within the model. The trend of counter-urbanisation witnessed in the UK from the 1960s until, in some cases, the start of the twenty-first century (Champion 2016), is thus not observed within our model. Historically, this phenomenon is complex and not uniform across the UK, though de-industrialisation is held primarily responsible for this 'urban exodus', a trend largely reversed by international migration, regeneration, gentrification, and the expansion of the university sector (Kalogirou 2005). Our use of a simple demographic model and a scaled down global economic model is not suitable for capturing these complex effects within this proof-of-concept. This demonstrates one of the drawbacks of a synthetic urban system based on UK wide data.

With a low birth rate, the urban system's population growth is sustained by inward migration. This is largely consistent with observed reality (Bocquier and Costa 2015). The expansion of the urban economy leads to the creation of more jobs and a positive feedback effect. This growth has negative environmental consequences, with the urbanisation of undeveloped land, and higher resource and food demands. There is a trade-off here within the model between human welfare and environmental impact, but the model in its current form is too abstract to explore this in detail.

The fraction of food that is imported into the urban system rises from $70 \%$ in 1980 through to $80-90+\%$ from the 
(a) Welfare Index (dimensionless)

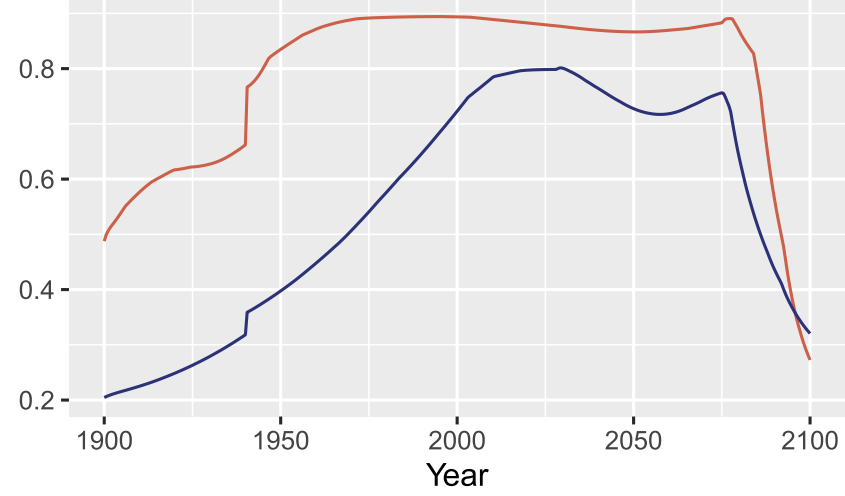

(c) Ecological footprint (dimensionless)

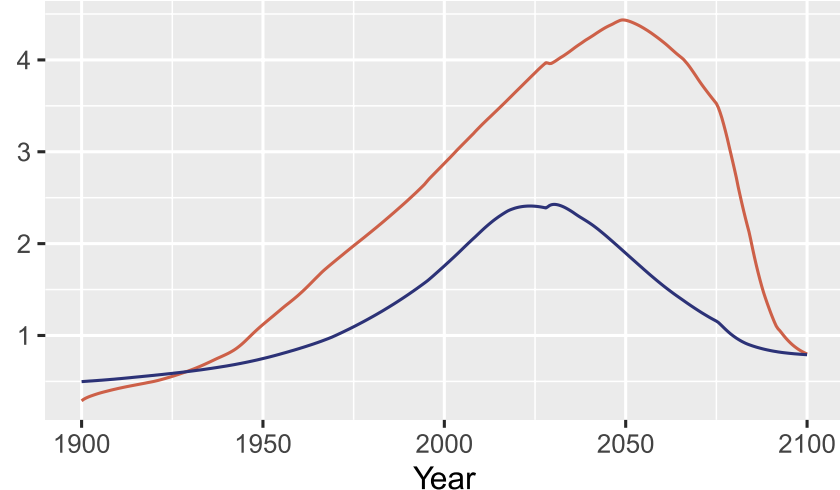

(e) Food per capita (veg equiv kg per year)

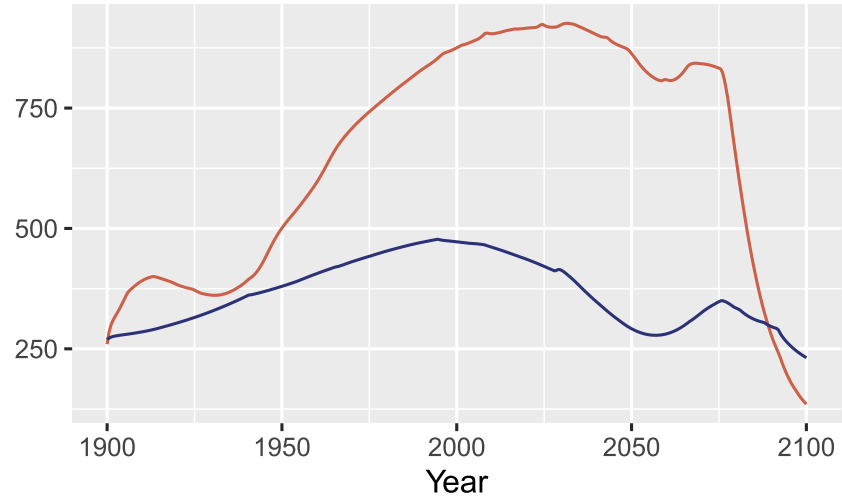

(b) Economic output per capita (\$ per person per year)

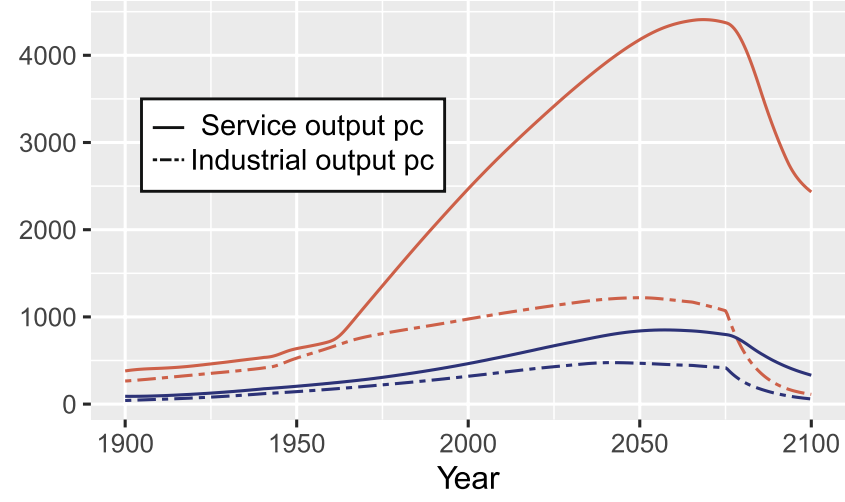

(d) Urban system population (dimensionless)

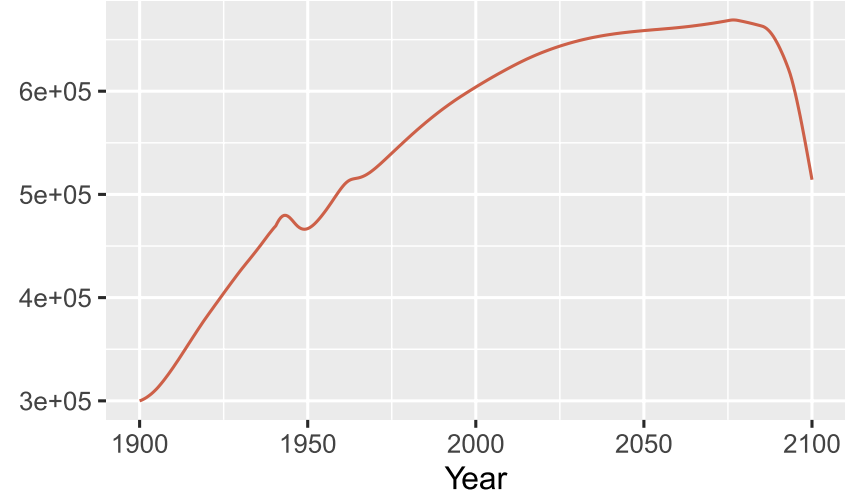

(f) Global population (dimensionless)

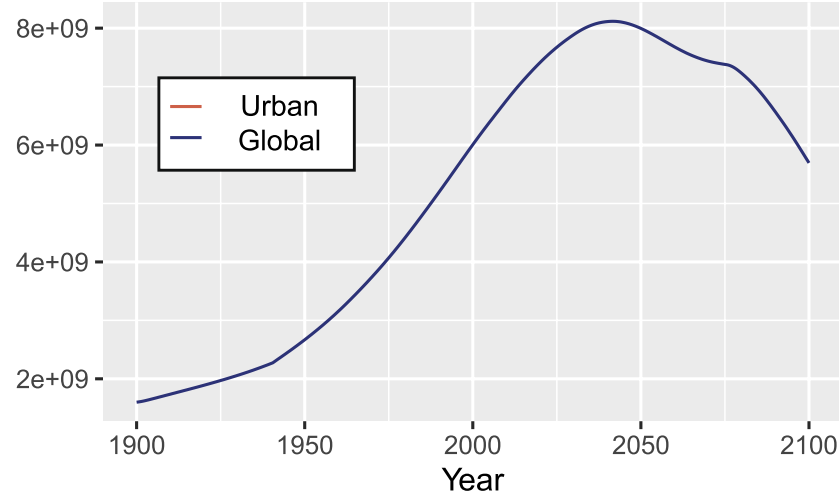

Fig. 7 Key outputs from our 'standard run', the red lines indicate urban parameter values with the blue lines representing corresponding global values. Note that the population parameters are displayed on separate scales due to the disparity in their order of magnitude

twenty-first century, ${ }^{4}$ as per our added causal structures this occurs due to the cost of importing food relative to producing it locally. Despite being relatively rich, the urban system

\footnotetext{
${ }^{4}$ Reliable quantification of this is difficult. Roughly half of food consumed in the UK is estimated to be produced domestically (DEFRA 2017). 'Local' is ill-defined though and the existence of an agricultural hinterland varying widely contextually renders a precise figure largely meaningless.
}

is unable to escape global events, with its economy experiencing the effects of a global decline from the 2070s. The reliance on imported food leads to a sharp decline in available food per capita and subsequently life expectancy. This demonstrates that whilst there are questions surrounding the 'sustainability' argument of the local food movement (Born and Purcell 2006), it remains important for resilience (Puma et al. 2015). The food consumption per capita (e) is double the global average for most of the twenty-first century; 


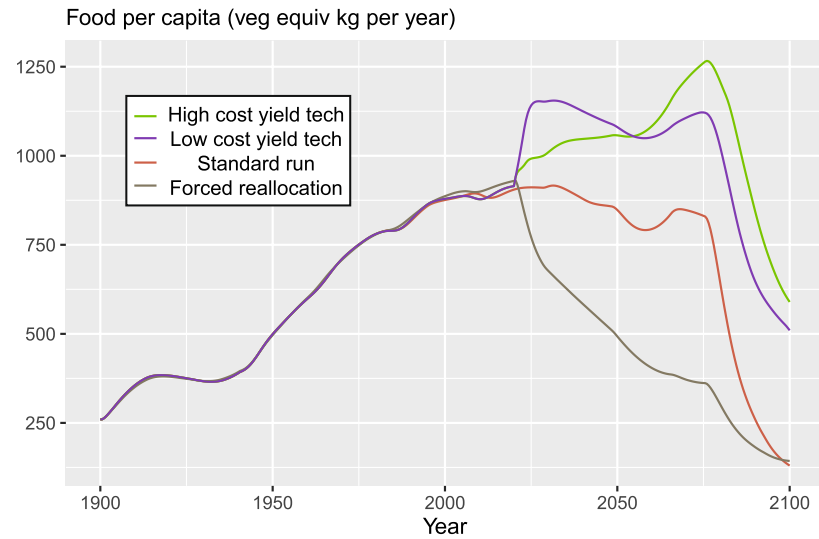

Fig. 8 Experiments with urban food production, displaying food per capita in vegetable-equivalent-kg per year within the urban system

since these are measured in terms of the total embodied energy via food-chains they are not directly comparable to data on calorie consumption. Using Shepon et al.'s (2018) values for lost calories and dietary composition data from National Geographic (2014), Purvis (2020) estimates figures of 'true' calorie consumption of approximately $5200 \mathrm{kcal}$ and $8500 \mathrm{kcal}$ for 2013 (translating to 542 and 885 veg equiv $\mathrm{kg}$ ). These roughly cohere to what is observed from these outputs, and World3's underestimation of global food per capita has previously been noted by Turner (2008).

The ecological footprint (c) of the simulated urban system is large, approximately 1.6 times the global average from World3-03 (compared to UK value 1.7 times global average in 2018 (Global Footprint Network 2018)). This large figure is primarily composed of contributions from absorption land required to mitigate urban pollution, and agricultural land for providing the urban food supply (approximately twice the pollution figure).

By qualitatively examining the scenarios illustrated in Fig. 7, we can see that the urban trajectory, despite its higher-than-average amplitude, follows a qualitatively similar path to the global trajectory. This is unsurprising, we have already seen within our model that the urban system is dependent on the wider global system for much of its food supply, as well as other resources. It is not just the global economic system upon which the urban is dependent, but global ecological and resource limits too.

\section{Subsequent scenarios}

The reference scenario assumes that no action is taken at the urban scale to address the large footprint or to prevent or mitigate economic collapse, either by considering its own evolution, or events at the wider global scale. Whether this represents a realistic assumption is a matter of debate. Regardless, the model represents a powerful tool to explore strategies that may be taken to respond to events across scales. This section therefore details the results of a series of experiments that were conducted following our standard run, exploring implications of coupling mechanisms. It is here that system dynamics modelling shows its true value, allowing us to explore causality and unintended consequences through cascading effects.

The tools available to us within this proof-of-concept modelling frame are largely limited to those added by Meadows et al. (2005), which include several structures for technological programmes, as well as policy measures, such as fertility control limits and agricultural land policy. We are (a) Economic output per capita (\$ per person per year)

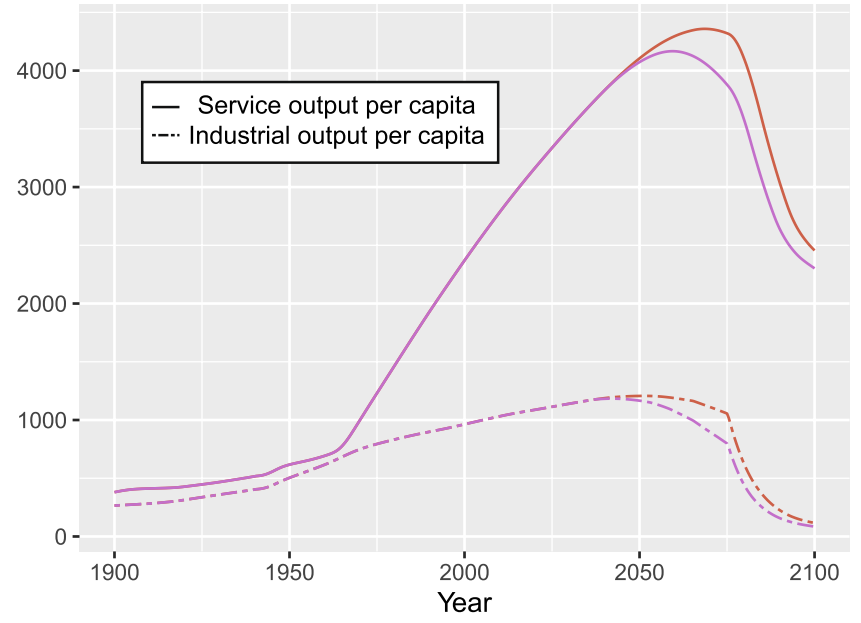

(b) Ecological footprint (dimensionless)

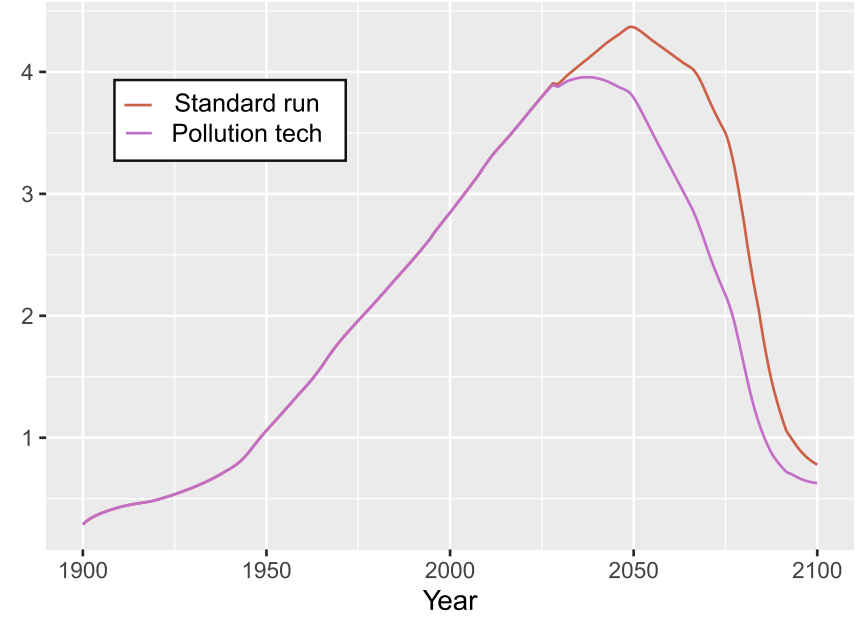

Fig. 9 Investment in pollution control technology. The figure displays urban system values for ecological footprint and economic output per capita in two scenario runs 
also able to switch on and off couplings between the different scalar hierarchies within the model, and to make numerical changes to various parameters. Whilst additional strategies may be considered by incorporating additional loops to the model structure, these are not explored at this stage. The scenarios presented in this paper are summarised in Table 2 which outlines a description and details of the parameters used to generate them.

\section{Urban food resilience}

The reference scenario experienced collapse partly due to the reliance of the urban system on imported food. What if it can produce a larger portion of its own food? Such an ambition would require sustained capital investment over time, so implementing it as a response to soaring global food costs is too late. What then if our urban system began to produce a greater proportion of its own food due to uncertainties about its own food security due to the increasingly evident effects of climate change (Sartison and Artmann 2020)? We thus modelled a scenario where in 2020 our urban system launches a policy encouraging local food production, with the ambitious goal of producing $50 \%$ of its own food by 2050.5

This scenario is somewhat difficult to implement in our current model due to the limitations of our economic subsystem (specifically the lack of differentiation between private and public capital). Figure 8 displays several iterations of outputs relating to this proposed intervention. Experimentation shows that if the policy is forced through demand without any investment in novel agricultural techniques, it leads to a poorer economy and less food, since there is limited arable land available to satisfy the demand for local food. Whilst this result hinges on our simplified economic model, and a rigid definition of 'local food', it illustrates the ability of a multi-scale integrated view to show unintended consequences of policy action. A second experiment accompanies this shift in demand with local investment in technologies, such as hydroponics, which act to increase yield by a factor of 10 (Barbosa et al. 2015). Whilst this boosts the urban food per capita for the next half century, the system is still impacted by the global decline as food imports become unaffordable, and the system must solely rely on the food it produces itself. The exact impact of this measure depends on the cost of the development scheme, with both high cost and low-cost solutions modelled, though

\footnotetext{
5 This choice of figures for this ambitious policy is largely arbitrary. A good overview for the potential of urban food production to build resilience may be found in Jensen \& Orfila (2021) who demonstrate that numerous uncertainties still exist in what is achievable in this respect. Nevertheless, their findings demonstrate that a 50\% figure isn't necessarily a widely unrealistic ambition.
}

the qualitative evolution is similar. The urban system may be considered more resilient under this local food programme, but its outcome is still sensitively dependent on the wider systems in which it sits.

\section{Urban pollution controls}

In a second set of scenarios, we explored measures to control 'persistent pollution' at the urban level. These pollution control measures, result in a portion of industrial output being invested each year in 'pollution technologies', which reduce the amount of pollution generated per unit of output by up to $4 \%$ a year (Meadows et al. 2005, p 210). This may be understood as a policy agreement which requires the local authority to make a fixed annual investment in research and development to create and implement these technologies. This is funded by some form of local corporation tax or levy, which distributes the cost across the local economy. Whilst these measures improve the immediate local environment, within our model they make little impact on the overall trajectory since they are overshadowed by a lack of action taken at the global level, e.g., to mitigate climate change. The results of this scenario in relation to the urban economic output and ecological footprint are shown in Fig. 9.

Whilst this outcome is a clear illustration of a tragedy of the commons, these measures to improve the health of urban populations: for measures begun in 2020, by 2060 life expectancy is 2 years higher than in the reference scenario where no measures are taken. Interestingly the cost of these measures in limiting the expansion of the urban economy leads to a relatively lower level of consumption, which itself acts to reduce the urban footprint. It is not surprising that a wealthier economy has a larger footprint; the downside of this scenario is that a relatively poorer urban system collapses faster during the global crisis, with less capital available to postpone these effects.

\section{Scenario findings: a sensitively dependent future?}

Both explorations of scenarios described above suggest that the evolution of the urban system is sensitively dependent on the evolution of the global system. Of course, the model output is a natural consequence of the coupling between systems that is present within the model itself. Therefore, an argument that was levelled at World3, that the model is predicated to collapse (Bardi 2011), is equally applicable here; our model is predicated to demonstrate coupling between systems across multiple scales. Yet this is not an exposé, we have described these coupling mechanisms within this paper and the accompanying Electronic Supplementary Material, and they follow a causal logic which we believe represents a simplified model of reality. Urban systems are deeply embedded within global systems, supply chains, and 
a globalised economy, and authors have written about this coupling in various guises for decades (Friedmann 1986; Brenner 2018). Our model demonstrates the power of system dynamics as a tool for exploring the consequences of the causal logic which already exists within our mental models.

\section{Discussion}

We have presented here a proof-of-concept multi-scale IAM for testing the impact of policy intervention at different scales in relation to urban sustainability. A reference scenario was detailed as well as the exploration of subsequent scenarios which attempted to move towards a more sustainable urban system through intervention. Whilst these scenarios come with the heavy disclaimer that our model is in its very early stages as a proof-of-concept and is reliant on the assumptions of a global model whose structure requires further refinement, they illustrate the potential of a multi-scale IAM for better understanding policy intervention in relation to urban sustainability. Through these we demonstrated that whilst action at the urban scale can act to boost the welfare of its citizens and reduce its ecological footprint, its long-term future is tightly coupled to evolution at a broader scale. Measures taken solely at the scale of a singular urban system at best only postpone the effects of global crisis, at worst they have unintended consequences which leave the system worse off than if no action had been taken. This emphasises the need for a multi-scalar approach, considering evolution at the global scale, but also action at intermediate scales, such as state, continental, or federal.

It should be noted that our experiments have been carried out within a global system that is predicated to collapse and takes almost no collective action to avoid this crisis or brace itself for turbulent times. Whether this is a fair representation of our future is a matter of perspective. As numerous scholars and activists emphasise, time is running out to avoid this trajectory. What our scenarios then have shown is that there is no path for urban sustainability in an unsustainable world, or that local sustainability is dependent on global sustainability. The urban system can build resilience, improve the health and wellbeing of its population, and brace itself, but action at higher scales is required to shield it fully, thus any suite of measures should consider joined-up policy formation across scales.

This discussion section presents the challenges of moving from a proof-of-concept multi-scale IAM to a more developed one, including a suitably enriched urban system to support the evaluation of a broader palette of policy interventions. These challenges present significant barriers, but we argue that they are not insurmountable, and regardless affect any approach which attempts to aid decision making through modelling potential urban futures.

\section{Challenges to operationalising a full multiscale model}

As a proof-of-concept, the model articulated in this paper is largely abstract and is some distance from a truly operational model. Several challenges exist in successfully making this transition relating to data requirements, decisions regarding boundaries, and the political dimension of such a modelling endeavour.

\section{Data and noise}

In creating a synthetic data set for our model based upon scaled national UK data, as described in "Data", we were able to focus on the model itself and the multi-scale coupling without getting lost in calibration. This is clearly not appropriate for operational use as it captures little of the local specificities that make each urban system unique. Data availability has come remarkably far since the first calibrations of the World 3 model in the early 1970s, with open data, 'big data', and novel avenues for collection (Satterthwaite 2010; Kitchin 2014; Rathore et al. 2018). Nevertheless, there remain specific issues for the approach we have outlined relating to the demand for data resolved at a fine spatial scale, both in terms of data availability and the inevitable uncertainty and noise which accompanies such data (Spielman 2017). These issues become increasingly problematic at finer scales, such as at the neighbourhood or community level, where data either does not exist or is closely safeguarded due to its sensitivity or commercial value (Elwood and Leszczynski 2011; Contreras et al. 2020). One potential solution to an absence of data lies in statistical methods which interpolate across missing data gaps and make inferences across spatial and temporal scales where necessary (Snyder 2001).

A finer scale also increases the noise within historical time series data; as noted in "A standard run", various urban areas in the UK witnessed a decline in population from the 1960s, primarily caused by de-industrialisation, though observed data is not uniform and remains context specific (Champion 2016). The modeller then faces the decision of whether the model should be able to reproduce fluctuations at timescales shorter than long term observed trends. Here it is not so much a question of calibrating parameters to fit the data, as identifying causal structures that can explain such historical fluctuations (Greca and Moreira 2000). 


\section{Boundaries}

Urban boundaries are multi-dimensional and may be thought of in physical, institutional, and functional terms (Purvis 2020). The institutional boundary, i.e., the boundary designating the area in political terms, is largely arbitrary in practice, yet paradoxically highly influential due to the direct impact of policy being largely constrained within these borders. Considering more appropriate physical or functional boundaries often necessitates crossing multiple jurisdictions with different data collection practices, and even competing political priorities. It is for this reason that most operationalisation of urban sustainability tends to focus on arbitrarily drawn institutional boundaries, notwithstanding it is within these that change may be more easily engendered as existing policy making apparatus tend to cohere to such boundaries (Shaw 2015).

Whilst a more idealised theoretical work may prefer physical boundaries (which are not without their own issues in defining), or even reject the notion of boundaries in their entirety, a pragmatic approach to identifying avenues for change must seriously engage with such inconvenient boundary decisions. It is the functional boundary that may make amends for this by capturing leakage effects or exporting of 'unsustainability' through a notion of 'interspatial' equity. Such boundary choices are integral to an understanding of urban sustainability which reflects on the urban system's place in the wider multi-scalar global system.

The construction of the urban scale model as an adaptation of a previously globally defined model confronted in the construction of our model we confronted the transition from closed to open functional boundaries. For the tangible subsystems, such as population and resources, this transition was straightforward. For the more abstract economic system however, clear definition across hierarchical scales is complex and requires a deeper theoretical grounding, Meadows et al.'s economic model proved an insufficient basis here for adaptation to multiple scales. The choice to develop a synthetic urban model within this work largely avoided the local specificities of using real urban physical and institutional boundaries, an operational model would have to confront these challenges more seriously.

\section{Depoliticisation}

Gómez-Baggethun and Naredo (2015) argue that a shift from a political to a technocratic sustainability discourse must be resisted, yet modelling approaches are often guilty of reducing sustainability to a technical challenge. Indeed, van Beek et al. (2020) question the ability of IAMs to conceive of more radical societal restructuring and suggest the need for modellers to engage more with a wider range of disciplines and stakeholders. This suggests a space for developing models which conceive of radical pathways beyond the current economic order rather than being constrained by current systems (Anderson and Jewell 2019). System dynamics, whilst being reductionist, remains more open to the political nature of sustainability and, in being manageably complex, lend themselves well to interactive development and use (Pruyt 2006). Whilst it is difficult to see system dynamics modelling as a radical emancipatory method (Crookes and Wit 2014), it certainly has potential to be used as part of a pluralistic toolkit (Lane 2001), particularly if social dimensions are better captured through stakeholder dialogue. In particular, there is space to develop a multi-scale model of the economic subsystem which resists the equilibrative optimal paradigm favoured in the mainstream IAM community.

The modeller has a duty to reflect on how their model may be mobilised for political aims in a manner that has adverse consequences (Palmer 2017). This is particularly pertinent for the work presented here which deals with sensitive issues, such as migration in an abstract manner, devoid of the human context. This highlights the importance of methodological pluralism, and the limitations of drawing firm conclusions from a single methodology, something which might be addressed in the participatory process.

\section{Building trust in model outputs}

A second set of challenges inherent to any modelling approach relates to trust in the model's outputs (Commenges et al. 2017). This becomes especially pertinent when not only do we as modellers have to trust the model, but we must build trust with those involved in the policy process. This is more than a 'validation' exercise; as the aphorism goes, "all models are wrong, but some models are useful". As suggested in "Methodology: adapting World3" then, the term 'validation' can often be an unhelpful notion (Barlas and Carpenter 1990). The key element in building trust in the model is to demonstrate its usefulness, as well as the production of 'meaningful' outputs. In its current iteration, our proof-of-concept model remains too abstract to be directly applied to a real system, even as we claim that its results are meaningful and useful for developing a deeper understanding of urban sustainability. Whilst there are numerous ways of improving model trustworthiness, we feel it is important to remain skeptical of all models and their outputs, however complex and 'trusted' a model is, it should only be a single part of a wider pluralistic toolkit.

\section{Model 'validation'}

Meadows et al. (1974) argue that the 'usefulness' of the model is more important than its ability to perfectly reproduce time series data (pp 24-25). Similarly, Ford (2010) argues that a more pragmatic question than "is the model 
valid?" is "is the model useful?" (p 163). This is a common modelling philosophy, and one that we share; Levins (1966) argues "all models leave out a lot and are in that sense false, incomplete, inadequate; the validation of a model is not that it is 'true' but that it generates testable hypotheses relevant to important problems" (p 430).

Building confidence in our models is a never-ending process, we can never say our model is 'valid', only that it has passed the tests we have subjected it to, or that we have revised and updated it with new data and information if it does not pass a test. For our proof-of-concept model, its 'usefulness' can be assessed by its ability to satisfy the purposes set out for it in "Modelling framework", i.e., producing reasonable output values for relevant phenomena whilst investigating a selection of scenarios. This necessitated ongoing 'face validation', i.e., persistent examination of whether the model structure and output results make sense (Ford 2010). Behaviour was also compared with the output of World3 scenarios to check whether expected qualitative similarity of output results was observed. Because our synthetic representation of the urban-scale system was based on scaled UK aggregate data we were able to use the raw time series for comparison. This confirmed that the model cohered quantitatively and qualitatively to available historical data relating to the level and sectoral composition of national economic output.

\section{Presentation of outputs}

Building trust and confidence comes with the need to clearly articulate what the outputs of our modelling exercise are and how they should be interpreted. It has been argued that a lack of clarity in this respect was a key reason why the $L t G$ studies received such a mixed response (Bardi 2011; Jackson and Webster 2016). van Beek et al. (2020) suggest that it took decades for global IAMs to gain the prominent role at the climate science-policy interface which they hold today. They argue that this place was achieved in part due to the long-term advocacy work and proactive anticipation of policy-relevance from the modelling community, as well as a clear demand for methods to balance the complexity of the socioeconomic aspects relating to climate change. A general 'trust in numbers' lends authority to quantitative forms of knowledge relating to climate change, something which must be engaged with in a critical and open manner (Wesselink et al. 2013).

It is useful to be reminded of Meadows et al. (2005)'s disclaimers. "We are not trying to predict the future" emphasises the 30-year update (p xvii), but "a range of alternative scenarios... of how the twenty-first century may evolve" ( $p$ xix). As well as stating, "we do not believe that available data and theories will ever permit accurate predictions of what will happen to the world over the coming century" (ibid.). As repeatedly stressed, their scenario outputs are not a "forecast". Furthermore, the scenario outputs display trends if no actions (or only certain predefined actions) are taken. Arguing that society would take steps to mitigate negative effects does not deny the 'veracity' of these outputs. This approach enables us to understand plausible futures that could evolve, to better guide and develop policy.

Thus, the language chosen to describe these scenarios is important. They are not predictions. This is in part due to the lack of fine grain data from which to calibrate the relations between variables and the initial system setup, and the fact that the model represents a simplified abstraction of the real system upon which it is based. Nevertheless, it has some basis in reality, from the calibration using real world data, and the theory behind its equations. A simplified abstraction allows the modeller to strip out noise and better analyse and understand the relation between a smaller number of key coupled variables; this allows focus to be given to pertinent high-level policy questions.

\section{Stakeholder engagement}

To move such a modelling exercise from the abstract to the empirical level, some form of engagement with relevant actors is required (Manetti 2011). This is a necessary step of forwarding our model beyond a proof-of-concept. The question of who relevant stakeholders are is a salient one, and may be largely informed by the research approach taken; Colvin et al. (2016) describe the process of identifying stakeholders as both an art and a science, with intuition and past experiences deemed as valid as a more systematic approach. Mitchell et al. (1997) categorise stakeholders in terms of power, legitimacy, and urgency, arguing that these attributes define the desirability of engaging with a particular actor. Such a framework however reinforces the marginalisation of those without power, thus alternative approaches exist seeking an equitable and socially just process with meaningful engagement and empowerment of the voiceless (SuarezBalcazar 2020). The identification of stakeholders then is as much political as it is a practical choice.

Aside from selection, barriers also exist to stakeholder engagement and the realisation of meaningful impact. These involve financial and time constraints, the mediation of competing views, communication barriers, and the navigation of institutional and legislative structures (Reynolds et al. 2006; Manetti 2011; Tseng and Penning-Rowsell 2012). These depend on context, with the openness of 'gatekeepers' and the culture surrounding access varying internationally (Tofarides 2017). Thus, a research design proposing linear 'stakeholder engagement' is insufficient, it must draw upon the literature from policy and management sciences (see, 
e.g., de Gooyert et al. (2017)), in order to anticipate and confront these challenges.

\section{To the future}

There are several directions that future evolution of our proof-of-concept model could be taken in. Ideally these should be determined in consultation with relevant stakeholders to ensure a focus on 'usefulness', although there are also merits to exploring theoretical questions in a more abstract manner. Of key importance is developing a multiscalar IAM which more fully conceptualises scales between the urban and global systems. Our national scale within this proof-of-concept was primarily limited to inputting and transforming national scale data; an internal structure would allow for better consideration of national policy leavers, and the coordination of higher level priorities, such as climate change commitments.

By moving away from the restrictive framework of World3 for defining the urban level system, there are numerous avenues that a more developed model could take. Foremost would be expanding on the 'urbanness' of the model by introducing more relevant sub-systems, such as energy, housing, or transport. This process would be aided by increasing the modularity of the model, though this may necessitate using a less restrictive software environment. Increased modularity would also encourage a more collaborative approach to model design, allowing subsystems to be adapted by other researchers in parallel. An evolution away from World3 also opens the modelling approach up to other simulation techniques, such as incorporating agent-based techniques (Duran-Encalada and Paucar-Caceres 2009). This would help to confront the limitations of system dynamics' aggregate approach, for example better reflecting internal inequalities using a synthetic population (Robinson 2019). Spatial disaggregation may also be considered within the urban system itself through consideration of a zonal model (Irwin et al. 2009). This would allow for exploration of spatial inequalities within the urban system whilst also facilitating more meaningful modelling, for example of land use and transport interactions.

Through co-ordinated stakeholder and 'expert' engagement, key urban functions and phenomena can be scoped out, and through collaboration with domain experts, theory may be developed for the integration of such factors into the existing urban system dynamics model. It is here where relevant expertise is important so that such a model may be grounded in both theory and reality. Co-specification with relevant policy makers could allow for a model to incorporate phenomena relevant for the testing of policy-based scenarios which are of interest locally. Any model developed collaboratively however needs to remain mindful of the power dynamics at play and should act to engage and empower marginalised groups.

\section{Conclusions}

This paper has presented a proof-of-concept integrated assessment model which couples an urban system to higher scales and explores the effects of policy action across these scales in relation to sustainability. Whilst we recommend caution in the interpretation of our scenario outputs, they suggest that the future of an individual urban system is sensitively dependent on the evolution of the global system. This may seem obvious to some readers, but it should not be under emphasised; whilst localised action can improve wellbeing and environmental quality on the ground, without coordinated action at the global scale the urban system is ultimately at the mercy of factors beyond its scale of influence.

In demonstrating the importance of holism and feedback effects between relevant sub-systems and hierarchical scales, we suggest that decision making in relation to the urban scale may be better facilitated through the consideration of multi-scale modelling. Such an approach would complement global IAM methods with a bottom-up approach, diversifying the toolkit for joined up policy thinking. Whilst there are considerable challenges to fully operationalising a model of this type in the form of data issues and model complexity, boundary definitions, building trust, and the inherent political nature of such an endeavour, they can and must be engaged with. It is our hope that such an approach could not only form part of a toolkit to aid decision making at the urban scale for a just transition to a more sustainable society, but further emphasise the necessity of coordinated action at the global scale to confront the existential challenges facing our planet.

Supplementary Information The online version contains supplementary material available at https://doi.org/10.1007/s11625-021-01080-0.

Acknowledgements Ben Purvis is grateful for the financial support of the Faculty of Social Sciences at the University of Sheffield. This work was also supported by the Engineering and Physical Sciences Research Council [Grant number 1643433]; and the Leverhulme Trust research programme grant 'Sustaining urban habitats: an interdisciplinary approach' [Grant number RP 2013-SL-015].

Open Access This article is licensed under a Creative Commons Attribution 4.0 International License, which permits use, sharing, adaptation, distribution and reproduction in any medium or format, as long as you give appropriate credit to the original author(s) and the source, provide a link to the Creative Commons licence, and indicate if changes were made. The images or other third party material in this article are included in the article's Creative Commons licence, unless indicated otherwise in a credit line to the material. If material is not included in 
the article's Creative Commons licence and your intended use is not permitted by statutory regulation or exceeds the permitted use, you will need to obtain permission directly from the copyright holder. To view a copy of this licence, visit http://creativecommons.org/licenses/by/4.0/.

\section{References}

Anderson K, Jewell J (2019) Debating the bedrock of climate-change mitigation scenarios. Nature 573:348-349. https://doi.org/10. 1038/d41586-019-02744-9

Angelo H, Wachsmuth D (2020) Why does everyone think cities can save the planet? Urban Stud 57:2201-2221. https://doi.org/10. $1177 / 0042098020919081$

Ansell T, Cayzer S (2018) Limits to growth redux: a system dynamics model for assessing energy and climate change constraints to global growth. Energy Policy 120:514-525. https://doi.org/10. 1016/j.enpol.2018.05.053

Bach M, Tustanovski E, Ip AWH et al (2019) System dynamics models for the simulation of sustainable urban development: a review and analysis and the stakeholder perspective. Kybernetes 49:460-504. https://doi.org/10.1108/K-04-2018-0210

Bagheri A, Hjorth P (2007) Planning for sustainable development: a paradigm shift towards a process-based approach. Sustain Dev 15:83-96. https://doi.org/10.1002/sd.310

Bardi U (2011) The limits to growth revisited. Springer, New York

Barlas Y, Carpenter S (1990) Philosophical roots of model validation: two paradigms. Syst Dyn Rev 6:148-166. https://doi.org/10. 1002/sdr.4260060203

Bocquier P, Costa R (2015) Which transition comes first? Urban and demographic transitions in Belgium and Sweden. Demogr Res 33:1297-1332

Born B, Purcell M (2006) Avoiding the local trap: scale and food systems in planning research. J Plan Educ Res 26:195-207. https:// doi.org/10.1177/0739456X06291389

Brenner N (2018) Debating planetary urbanization: for an engaged pluralism. Environ Plan D 36:570-590. https://doi.org/10.1177/ 0263775818757510

Brenner N, Schmid C (2015) Towards a new epistemology of the urban? City 19:151-182. https://doi.org/10.1080/13604813. 2015.1014712

Capellán-Pérez I, de Blas I, Nieto J et al (2020) MEDEAS: a new modeling framework integrating global biophysical and socioeconomic constraints. Energy Environ Sci 13:986-1017. https:// doi.org/10.1039/C9EE02627D

Cauvain J (2018) Social sustainability as a challenge for urban scholars. City 22:595-603. https://doi.org/10.1080/13604813.2018. 1507113

Champion T (2016) Internal migration and the spatial distribution of population. In: Falkingham J (ed) Population change in the United Kingdom. Rowman \& Littlefield

Clayton N, Mandair R (2012) Cities outlook 1901. Centre for Cities

Cohen M (2017) A systematic review of urban sustainability assessment literature. Sustainability 9:2048. https://doi.org/10.3390/ su9112048

Cole HSD, Freeman C, Jahoda M, Pavitt KLR (1973) Models of doom: a critique of the limits to growth. Universe Books, New York

Colvin RM, Witt GB, Lacey J (2016) Approaches to identifying stakeholders in environmental management: insights from practitioners to go beyond the 'usual suspects.' Land Use Policy 52:266276. https://doi.org/10.1016/j.landusepol.2015.12.032

Commenges H, Tomasoni L, Seigneur C et al (2017) Who is the expert? Integrated urban modeling and the reconfiguration of expertise. J Urban Technol 24:89-108. https://doi.org/10.1080/ 10630732.2017.1284990

Contreras D, Chamorro A, Wilkinson S (2020) Review article: The spatial dimension in the assessment of urban socio-economic vulnerability related to geohazards. Nat Hazards Earth Syst Sci 20(6):1663-1687. https://doi.org/10.5194/nhess-20-1663-2020

Crookes DJ, Wit MPD (2014) Is system dynamics modelling of relevance to neoclassical economists? S Afr J Econ 82:181-192. https://doi.org/10.1111/saje.12038

de Gooyert V, Rouwette E, van Kranenburg H, Freeman E (2017) Reviewing the role of stakeholders in operational research: a stakeholder theory perspective. Eur J Oper Res 262:402-410. https://doi.org/10.1016/j.ejor.2017.03.079

DEFRA (2017) Food Statistics in your pocket 2017-Global and UK supply. In: GOV.UK. https://www.gov.uk/government/publi cations/food-statistics-pocketbook-2017/food-statistics-in-yourpocket-2017-global-and-uk-supply. Accessed 21 Sep 2020

Duran-Encalada JA, Paucar-Caceres A (2009) System dynamics urban sustainability model for Puerto Aura in Puebla, Mexico. Syst Pract Act Res 22:77-99. https://doi.org/10.1007/ s11213-008-9114-8

Eker S, Slinger J, van Daalen E, Yücel G (2014) Sensitivity analysis of graphical functions. Syst Dyn Rev 30:186-205. https://doi. org/10.1002/sdr.1518

Elwood S, Leszczynski A (2011) Privacy, reconsidered: new representations, data practices, and the geoweb. Geoforum 42:6-15. https://doi.org/10.1016/j.geoforum.2010.08.003

Etzo I (2008) Internal migration: a review of the literature. MPRA paper. University Library of Munich

Fiddaman T (2010) MetaSD: WORLD3-03. In: MetaSD. https://metasd.com/2010/04/world3-03/. Accessed 13 Dec 2021

Ford A (2010) Modeling the environment, 2nd edn. Island Press, Washington

Forrester JW (2007) System dynamics-a personal view of the first fifty years. Syst Dyn Rev 23:345-358. https://doi.org/10.1002/ sdr.382

Friedmann J (1986) The World City hypothesis. Dev Change 17:69-83. https://doi.org/10.1111/j.1467-7660.1986.tb00231.x

Fujita M, Krugman P (1995) When is the economy monocentric?: von Thünen and Chamberlin unified. Reg Sci Urban Econ 25:505528. https://doi.org/10.1016/0166-0462(95)02098-F

Global Footprint Network (2018) National footprint accounts 2018. Global Footprint Network, London

Gómez-Baggethun E, Naredo JM (2015) In search of lost time: the rise and fall of limits to growth in international sustainability policy. Sustain Sci 10:385-395. https://doi.org/10.1007/ s11625-015-0308-6

Greca IM, Moreira MA (2000) Mental models, conceptual models, and modelling. Int J Sci Educ 22:1-11. https://doi.org/10.1080/ 095006900289976

Heath AW, Stappenbelt B, Ros M (2019) Uncertainty analysis of the limits to growth model: sensitivity is high, but trends are stable. Gaia 28:275-283. https://doi.org/10.14512/gaia.28.3.8

Irwin EG, Jayaprakash C, Munroe DK (2009) Towards a comprehensive framework for modelling urban spatial dynamics. Landsc Ecol 24:1223-1236. https://doi.org/10.1007/s10980-009-9353-9

Jackson T, Webster R (2016) Limits revisited: a review of the limits to growth debate. APPG on Limits to Growth

Jensen PD, Orfila C (2021) Mapping the production-consumption gap of an urban food system: an empirical case study of food security and resilience. Food Sec 13:551-570. https://doi.org/10.1007/ s12571-021-01142-2

Kalogirou S (2005) Examining and presenting trends of internal migration flows within England and Wales. Popul Space Place 11:283297. https://doi.org/10.1002/psp.376 
Kidwai A, Saraph A (2016) Use of archetypal structures in urban dynamics. Syst Pract Act Res 29:583-595

Kitchin R (2014) The real-time city? Big data and smart urbanism. GeoJournal 79:1-14. https://doi.org/10.1007/s10708-013-9516-8

Kulu H (2013) Why do fertility levels vary between urban and rural areas? Reg Stud 47:895-912. https://doi.org/10.1080/00343404. 2011.581276

Lages Barbosa G, Almeida Gadelha FD, Kublik N et al (2015) Comparison of land, water, and energy requirements of lettuce grown using hydroponic vs. conventional agricultural methods. Int J Environ Res Public Health 12:6879-6891. https://doi.org/10. 3390/ijerph120606879

Lane DC (2001) Rerum cognoscere causas: part I-how do the ideas of system dynamics relate to traditional social theories and the voluntarism/determinism debate? Syst Dyn Rev 17:97-118. https:// doi.org/10.1002/sdr.209

Lane DC (2008) The emergence and use of diagramming in system dynamics: a critical account. Syst Res Behav Sci 25:3-23. https:// doi.org/10.1002/sres.826

Lane DC, Videira N (2019) Modelling sustainability pathways: bridging science, policy, and society. Syst Res Behav Sci 36:147-155. https://doi.org/10.1002/sres.2586

Levins R (1966) The strategy of model building in population biology. American Scientist 54:421-431

Lumley S, Armstrong P (2004) Some of the nineteenth century origins of the sustainability concept. Environ Dev Sustain 6:367378. https://doi.org/10.1023/B:ENVI.0000029901.02470.a7

Macmillan A, Woodcock J (2017) Understanding bicycling in cities using system dynamics modelling. J Transp Health 7:269-279. https://doi.org/10.1016/j.jth.2017.08.002

Manetti G (2011) The quality of stakeholder engagement in sustainability reporting: empirical evidence and critical points. Corp Soc Responsib Environ Manag 18:110-122. https://doi.org/10. $1002 / \mathrm{csr} .255$

Meadows DH, Meadows DL, Randers J, Behrens WW (1972) The limits to growth. Universe Books, New York

Meadows DL, Behrens WW III, Meadows DH et al (1974) Dynamics of growth in a finite world. Wright-Allen Press Inc, Cambridge

Meadows DH, Richardson JM, Bruckmann G (1982) Groping in the dark: the first decade of global modelling. Wiley, Chichester

Meadows DH, Meadows D, Randers J (1992) Beyond the limits: global collapse or a sustainable future. Earthscan, London

Meadows D, Randers J, Meadows D (2005) Limits to growth: the 30-year update. Earthscan, London

Mitchell RK, Agle BR, Wood DJ (1997) Toward a theory of stakeholder identification and salience: defining the principle of who and what really counts. Acad Manag Rev 22:853-886. https://doi.org/10.2307/259247

Nabavi E, Daniell KA, Najafi H (2017) Boundary matters: the potential of system dynamics to support sustainability? J Clean Prod 140:312-323. https://doi.org/10.1016/j.jclepro.2016.03.032

National Geographic (2014) What the World Eats. In: National geographic. http://www.nationalgeographic.com/what-the-worldeats/. Accessed 24 Sep 2020

Nordhaus WD (1973) World dynamics: measurement without data. Econ J 83:1156-1183. https://doi.org/10.2307/2230846

Nordhaus W (2013) Integrated economic and climate modelling. In: Dixon PB, Jorgenson DW (eds) Handbook of computable general equilibrium modeling. Elsevier, pp 1069-1131

Nordhaus WD, Stavins RN, Weitzman ML (1992) Lethal model 2: the limits to growth revisitied. Brook Pap Econ Act 1992:1-59

Office for National Statistics (2019) Births in England and Wales: 2018. Office for National Statistics

Office for National Statistics (2016) Internal migration, England and Wales: Year Ending June 2015. Office for National Statistics
Opp SM (2017) The forgotten pillar: a definition for the measurement of social sustainability in American cities. Local Environ 22:286-305. https://doi.org/10.1080/13549839.2016.1195800

Palmer E (2017) Beyond proximity: consequentialist ethics and system dynamics. Nordic J Appl Ethics. https://doi.org/10.5324/ eip.v11i1.1978

Pasqualino R, Jones AW (2020) Resources, financial risk and the dynamics of growth. Routledge, Abingdon

Pasqualino R, Jones AW, Monasterolo I, Phillips A (2015) Understanding global systems today-a calibration of the world3-03 model between 1995 and 2012. Sustainability 7:9864-9889. https://doi.org/10.3390/su7089864

Pauliuk S, Arvesen A, Stadler K, Hertwich EG (2017) Industrial ecology in integrated assessment models. Nat Clim Chang 7:13-20. https://doi.org/10.1038/nclimate3148

Pruyt E (2006) What is system dynamics ? A paradigmatic inquiry structure, methodology, method, or a set of techniques. Proceedings of the International System Dynamics Conference, Nijmegen, 2006.

Puma MJ, Bose S, Chon SY, Cook BI (2015) Assessing the evolving fragility of the global food system. Environ Res Lett 10:024007. https://doi.org/10.1088/1748-9326/10/2/024007

Purvis B (2020) Operationalising 'Urban Sustainability': defining, measuring and modelling. PhD Thesis. University of Nottingham

Purvis B (2021) Modelling global futures: a comparison of "Limits to Growth" and the use of integrated assessment models within the climate literature. In: 2021 Conference of the system dynamics society

Randers J (2012) 2052: a global forecast for the next forty years. Chelsea Green Pub, White River Junction, Vt

Rathore MM, Paul A, Hong W-H et al (2018) Exploiting IoT and big data analytics: defining smart digital city using real-time urban data. Sustain Cities Soc 40:600-610. https://doi.org/10.1016/j. scs.2017.12.022

Ravetz J (1998) Integrated assessment models—-from global to local. Impact Assess Project Apprais 16:147-154. https://doi.org/10. 1080/14615517.1998.10590200

Reynolds SJ, Schultz FC, Hekman DR (2006) Stakeholder theory and managerial decision-making: constraints and implications of balancing stakeholder interests. J Bus Ethics 64:285-301. https:// doi.org/10.1007/s10551-005-5493-2

Robinson D (2019) Integrated resource flow modelling of the urban built environment. In: Hensen JLM, Lamberts R (eds) Building performance simulating for design and operation, 2nd edn. Routledge, Abingdon, pp 441-468

Sartison K, Artmann M (2020) Edible cities-an innovative naturebased solution for urban sustainability transformation? An explorative study of urban food production in German cities. Urban for Urban Green 49:126604. https://doi.org/10.1016/j. ufug.2020.126604

Satterthwaite D (2010) Urban myths and the mis-use of data that underpin them. In: WIDER working paper

Shaw K (2015) Planetary urbanisation: what does it matter for politics or practice? Plan Theory Pract 16(4):588-593

Shepon A, Eshel G, Noor E, Milo R (2018) The opportunity cost of animal based diets exceeds all food losses. PNAS 115:3804-3809. https://doi.org/10.1073/pnas.1713820115

Snyder R (2001) Scaling down: the subnational comparative method. St Comp Int Dev 36:93-110. https://doi.org/10.1007/BF02687586

Spielman SE (2017) The potential for big data to improve neighborhood-level census data. In: Thakuriah P, Tilahun N, Zellner M (eds) Seeing cities through big data: research, methods and applications in urban informatics. Springer, Cham, pp 99-111

Sterman JD (2000) Business dynamics-systems thinking and modeling for a complex world. Irwin McGraw-Hill, Boston 
Suarez-Balcazar Y (2020) Meaningful engagement in research: community residents as co-creators of knowledge. Am J Community Psychol 65:261-271. https://doi.org/10.1002/ajcp.12414

Tan Y, Jiao L, Shuai C, Shen L (2018) A system dynamics model for simulating urban sustainability performance: a China case study. J Clean Prod 199:1107-1115. https://doi.org/10.1016/j.jclepro. 2018.07.154

Thomas R, Dimsdale N (2017) A Millennium of UK data. Bank of England OBRA dataset. https://www.bankofengland.co.uk/stati stics/research-datasets. Accessed 13 Dec 2021

Tofarides M (2017) Urban policy in the European union: a multi-level gatekeeper system. Routledge

Tseng C-P, Penning-Rowsell EC (2012) Micro-political and related barriers to stakeholder engagement in flood risk management. Geogr J 178:253-269. https://doi.org/10.1111/j.1475-4959.2012. 00464.x

Turner G (2008) A comparison of the limits to growth with 30 years of reality. Glob Environ Change 18:397-411. https://doi.org/10. 1016/j.gloenvcha.2008.05.001

Turner GM (2012) On the cusp of global collapse? Updated comparison of the Limits to Growth with historical data. GAIA 21:116124. https://doi.org/10.14512/gaia.21.2.10

UN (2017) The new urban agenda. Habitat III Secretariat

UN (2015) Transforming our world: the 2030 agenda for sustainable development; resolution adopted by the General Assembly on 25 September 2015 (A/RES/70/1)
UNDP (2020) Human development report 2020. United Nations Development Programme, New York

van Beek L, Hajer M, Pelzer P et al (2020) Anticipating futures through models: the rise of integrated assessment modelling in the climate science-policy interface since 1970. Glob Environ Change 65:102191. https://doi.org/10.1016/j.gloenvcha.2020.102191

Ventana Systems (2020) Ventity. https://ventity.biz/. Accessed 21 May 2020

Verburg PH, Dearing JA, Dyke JG et al (2016) Methods and approaches to modelling the anthropocene. Glob Environ Change 39:328340. https://doi.org/10.1016/j.gloenvcha.2015.08.007

Wesselink A, Buchanan KS, Georgiadou Y, Turnhout E (2013) Technical knowledge, discursive spaces and politics at the sciencepolicy interface. Environ Sci Policy 30:1-9. https://doi.org/10. 1016/j.envsci.2012.12.008

Yeager L, Fiddaman T, Peterson D (2014) Entity-based system dynamics. In: Proceedings of the international system dynamics conference, Delft, 2014. Harvard, MA

Publisher's Note Springer Nature remains neutral with regard to jurisdictional claims in published maps and institutional affiliations. 